(2) Open Access Full Text Article

\title{
Intravascular Papillary Endothelial Hyperplasia Mimicking Vaginal Malignant Tumor in a Post-Radiotherapy Patient: A Case Report and Literature Review
}

Ying-Xin Gong ${ }^{1} *$

Yu Xie (D) ${ }^{1, *}$

Limei Chen ${ }^{1,2}$

Long Sui $\mathbb{D}^{1,2}$

'Obstetrics and Gynecology Hospital of Fudan University, Shanghai, 2000II, People's Republic of China; ${ }^{2}$ Shanghai Key Laboratory of Female Reproductive Endocrine Related Diseases, Shanghai, 2000 II, People's Republic of China

*These authors contributed equally to this work
Correspondence: Long Sui

Obstetrics and Gynecology Hospital of Fudan University, 419 Fangxie Road, Shanghai, 2000II, People's Republic of China

Email suilong@fudan.edu.cn

\begin{abstract}
Intravascular papillary endothelial hyperplasia (IPEH) is a rare benign lesion that occurs in the soft tissue of any site, including the central nervous system, extremities, head, and female reproductive system. But no case occurred in vagina was reported previously. Here, we report a case of vaginal IPEH in a 54-year-old woman who has a history of radical hysterectomy for endometrial cancer with postoperative radiotherapy. She was positive for high-risk human papillomavirus (HR-HPV) with cytology result as low-grade squamous intraepithelial lesion (LSIL), and pathology from colposcopy-directed biopsy (CDB) presented suspicious high-grade squamous intraepithelial lesion (HSIL). The colposcopy showed an $8 \mathrm{~mm}$ neoplasm at the right apical angle of vagina. The diagnosis of IPEH was confirmed by biopsy pathology and immunohistochemistry. As the lesion was benign and rather small, we discharged the patient with annual follow-up. The case illuminated that attention should be paid to "HSIL" patients after radiotherapy to exclude the incidence of benign IPEH.
\end{abstract}

Keywords: case report, intravascular papillary endothelial hyperplasia, radiotherapy, vagina, endometrial neoplasms

IPEH, also known as Masson's tumor, is a rare hemangioma that occurred mainly in vessels, but it was also reported in head, extremities, breast, female vulva, etc. ${ }^{1-4}$ It is considered as a benign tumor originated in vascular endothelium that presented excessive hyperplasia and papillary formation. Most cases occur without a definite etiology, and about $30 \%$ of cases are post-trauma and have a history of vascular diseases. $^{5}$ The extracranial Masson's tumor presents a slow-growing and asymptomatic characteristic with the clinical feature as a small, firm, non-pulsatile, slightly elevated mass with a red or blue coloration. Here, we report a case with colposcopic finding as suspicious HSIL but diagnosed as benign IPEH by pathology and immunohistochemistry.

\section{Case Report}

A 54-year-old woman with a history of endometrial carcinoma presented with suspicious HISL came to our hospital. She had hysterectomy and bilateral salpingooophorectomy in 2016 with regular chemoradiotherapy (25 radiotherapies with 2 brachytherapy). Her postoperative follow-up showed HR-HPV positive, and the 

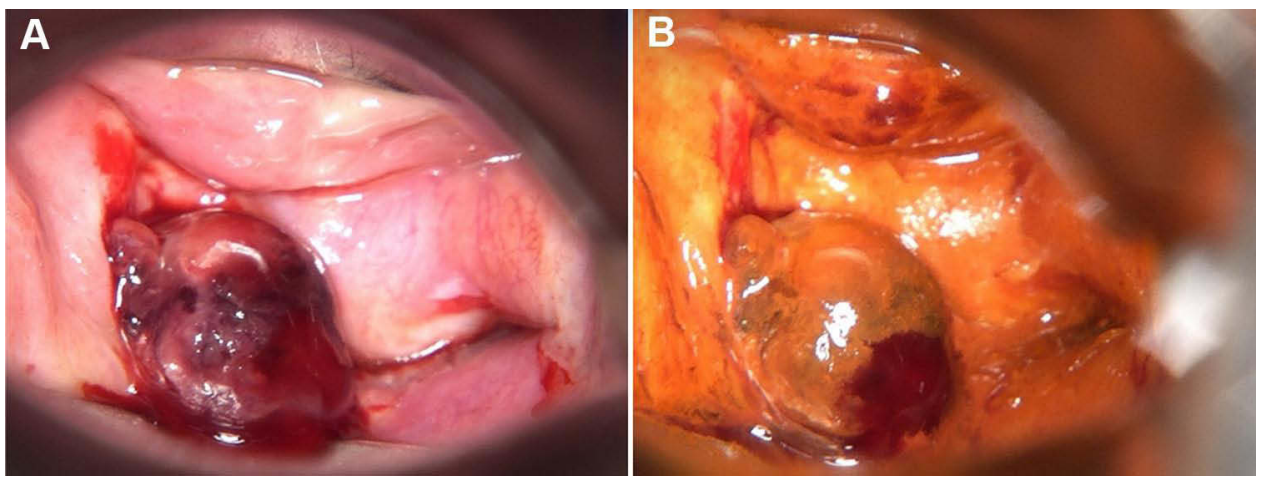

Figure I Colposcopes view of the lesion. (A) An 8-millimeter-diameter intravascular papillary endothelial hyperplasia in the right apical angle of the vagina with medium amount of blood. The lesion is red to purple coloration, and a medium amount of blood was seen. (B) lodine staining of the lesion.

ThinPrep cytologic test (TCT) result was LSIL. The pathology from CDB by another hospital implied suspicious HISL in April 2019. In July 2020, the colposcopy in our center detected a neoplasm at the right apical angle of vagina. The patient was then recommended for laser treatment in case of malignancy. During the operation, an 8-millimeter-diameter neoplasm at the right apical angle of vagina was seen (Figure 1). The subsequent pathologic result of CDB presented IPEH, and the immunohistochemical result was CD31(+), CD34(+), AE1/AE3(-), and $\mathrm{Ki}-67(+, 5 \%)$ (Figure 2). After reconfirmation with pathologists, we affirmed the neoplasm was a benign hemangioma, which was dispensable for extra therapy. The woman was then discharged with regular follow-up.

\section{Discussion}

IPEH was first reported in 1923 by Pierre Masson, the histologic hallmark of which was a constitutive thrombus within the vascular with endothelial cell proliferation. ${ }^{4,6}$ It can be divided into three types. The primary form occurred in dilated vessels, the secondary form presented in variceal vessels, hemangioma, inflammatory granuloma, vascular

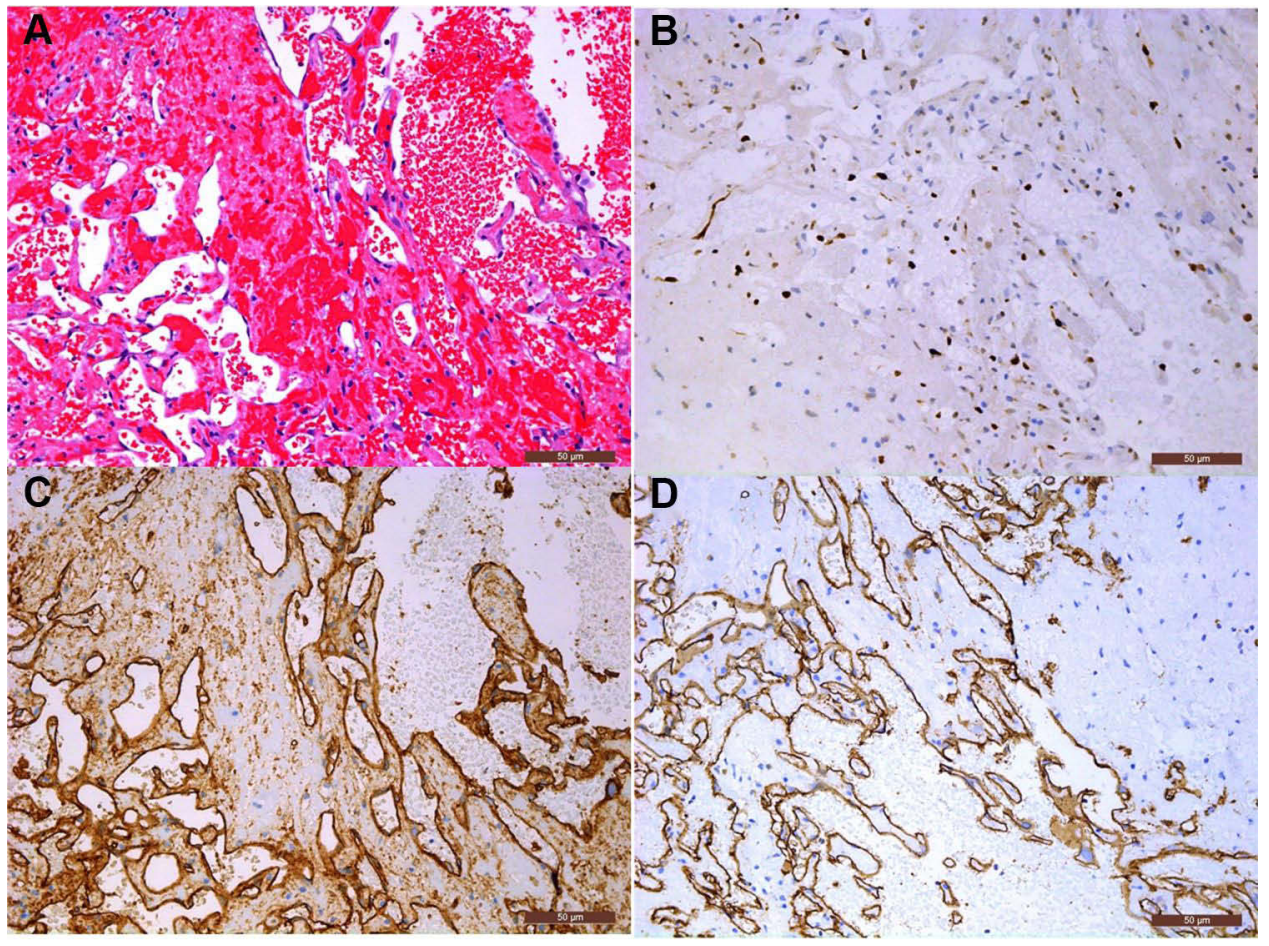

Figure 2 Pathology and immunohistochemistry result (200x). (A) Microscopic finding presents proliferation of erythrocytes within a dilated vascular structure. (B) Ki-67 labeling index was about 5\%. Immunohistochemistry shows the tissue was positive for CD3I (C) and CD34 (D). 
tumor, and the extravascular Masson's tumor is extremely rare, which can occur in multiple sites throughout the body.

The rare extravascular form has been reported to happen in periocular region which causes reversible vision loss and proptosis, mandible, and oral region. ${ }^{2,7-9}$ In the female reproductive system, three vulval cases, two ovarian cases and one cervical case of IPEH occurred have been reported, the common therapy was complete excision of the lesion (Table 1). In ovarian IPEH, the lesion was prominently larger and in one case it was mistaken with a malignant tendency. And the other case reported a mixed neoplasm of malignant mucinous borderline ovarian tumor and IPEH, which hinted the possibility of simultaneous incidence of malignant tumor and benign Masson's tumor. In IPEH reported in the cervix, the patient was in gestation and the tumor enlarged fast, growing from $3 \mathrm{~cm}$ to $7 \mathrm{~cm}$ in 8 weeks under the environment of high levels of estrogen and progesterone. The lesion was positive for CD31, CD34, and factor VIII, negative for epithelial membrane antigen, and Ki-67 labeling index was $1 \%$, which was consistent with our case. ${ }^{10}$ The pathological result was of the best diagnostic value to identify IPEH, and CD31 and CD34 in immunohistochemistry were used to remark the vascular endothelium. ${ }^{11}$ Considering the prominent symptoms as vaginal bleeding and pain, the excision of the lesion followed by suture of the anterior cervical lip was implemented during pregnancy, ensuing favorable maternal and fetal prognosis. The patient in our case was asymptomatic and the lesion was small, hence we did not perform excision.

Irradiation has proved to be the risk factor of its induction and IPEH in the central nervous system, bladder after radiotherapy has also been reported. ${ }^{12,13}$ IPEH sometimes can be misdiagnosed as radiotherapy-associated malignant tumor such as angiosarcoma. Two cases reported postradiotherapy breast cancer patients with IPEH, in which the author differentiated IPEH and angiosarcomas by its clear border and non-invasive feature and macroscopic absence of atypia, necrosis, pleomorphism. ${ }^{14,15}$ However, adjuvant radiotherapy may be required in intracranial Masson's tumor to prevent recurrence or to treat patients whose lesion cannot achieve radical excision. ${ }^{16-18}$ The patient in our case has undergone 25 courses of radiotherapy including 2 brachytherapy, which might be the predisposing cause of IPEH.

\section{Conclusion}

Radiotherapy can induce the occurrence of IPEH, which can be misdiagnosed as malignant tumor which results in inappropriate treatment. To differentiate it from other malignant tumors, biopsy pathology and immunohistochemistry need to be applied. The treatment of IPEH is mainly complete local excision, but asymptomatic small lesions can adapt conserved therapy and continuously following up.

Table I Summary of Reports of Masson's Tumor Occurred in the Female Reproductive System

\begin{tabular}{|c|c|c|c|c|c|}
\hline Reference & $\begin{array}{l}\text { Age } \\
\text { (Years) }\end{array}$ & Region & Symptom & Size & Treatment \\
\hline $\begin{array}{l}\text { Kim et al } \\
(2014)^{19}\end{array}$ & 37 & Vulva & $\begin{array}{l}\text { A palpable mass with } \\
\text { intermittent vulvar pain }\end{array}$ & $30 \times 20 \mathrm{~mm}$ & Excision \\
\hline $\begin{array}{l}\text { Beutler et al } \\
(2016)^{4}\end{array}$ & 32 & Vulva & Painless, black papule & $3 \times 2 \mathrm{~mm}$ & Excisional biopsy \\
\hline $\begin{array}{l}\text { Nwokolo et al } \\
(2020)^{20}\end{array}$ & 35 & Vulva & $\begin{array}{l}\text { Tender mass with worsening } \\
\text { pain }\end{array}$ & $20 \times 30 \mathrm{~mm}$ & Excision \\
\hline $\begin{array}{l}\text { Sherring et al } \\
(2020)^{21}\end{array}$ & 44 & $\begin{array}{l}\text { Left } \\
\text { ovary }\end{array}$ & Intermittent pelvic discomfort & $200 \times 180 \times 95 \mathrm{~mm}$ & $\begin{array}{l}\text { Hysterectomy, bilateral salpingo- } \\
\text { oophorectomy, and omentectomy }\end{array}$ \\
\hline $\begin{array}{l}\text { Sherring et al } \\
(2020)^{21}\end{array}$ & 57 & $\begin{array}{l}\text { Left } \\
\text { ovary }\end{array}$ & Increasing abdominal girth & $260 \times 225 \times 165 \mathrm{~mm}$ & $\begin{array}{l}\text { Hysterectomy, bilateral salpingo- } \\
\text { oophorectomy, and omentectomy }\end{array}$ \\
\hline $\begin{array}{l}\text { Susini et al } \\
(2010)^{10}\end{array}$ & 40 & $\begin{array}{l}\text { Uterine } \\
\text { cervix }\end{array}$ & Severe pain and vaginal bleeding & $70 \mathrm{~mm}$ & Excision \\
\hline
\end{tabular}

Abbreviations: IPEH, intravascular papillary endothelial hyperplasia; HPV, human papillomavirus; NS, not state; HHV, human herpesvirus. 


\section{Ethical Approval and Consent to Participate}

Institutional review board/ethics committee approval was obtained from Fudan University Obstetrics and Gynecology Hospital for this study (reference number: Kyy2018-81) and written informed consent was obtained from the patient for publication of this report and accompanying images.

\section{Acknowledgments}

This work was supported by the National Natural Science Foundation of China (Grant No. 81701398) and Science and Technology Commission of Shanghai Municipality (No. 18411963600). The authors thank the Shanghai Key Laboratory of Female Reproductive Endocrine Related Diseases.

\section{Disclosure}

The authors declare that they have no conflicts of interest and nothing to disclose.

\section{References}

1. Patai BB, Peterfy N, Szakacs N, et al. Papillary endothelial hyperplasia (masson tumor) of the hand. Surgical and pathological consideration from seven cases using new vascular markers. Pathol Oncol Res. 2020;26(4):2083-2090. doi:10.1007/s12253-020-00838-8

2. Clasen CV, Gomes APN, Galdino Dos Santos L, et al. Intravascular papillary endothelial hyperplasia in the oral mucosa and jawbones: a collaborative study of 20 cases and a systematic review. $J$ Oral Pathol Med. 2020.

3. Branton PA, Lininger R, Tavassoli FA. Papillary endothelial hyperplasia of the breast: the great impostor for angiosarcoma: a clinicopathologic review of 17 cases. Int J Surg Pathol. 2003;11 (2):83-87. doi:10.1177/106689690301100203

4. Beutler BD, Cohen PR. Intravascular papillary endothelial hyperplasia of the vulva: report of a patient with masson tumor of the vulva and literature review. Dermatol Online J. 2016;22(5):13030. doi:10.5070/ D3225030943

5. Sasso SE, Naspolini AP, Milanez TB, et al. Masson's tumor (intravascular papillary endothelial hyperplasia). An Bras Dermatol. 2019;94 (5):620-621. doi:10.1016/j.abd.2019.09.013

6. Masson P. Hemangioendotheliome vegetant intravasculaire. Bull Mem Soc Ant. 1923;93:517-523.

7. Vempuluru VS, Jakati S, Kaliki S. Intravascular papillary endothelial hyperplasia: a rare cause of painful proptosis. Ophthalmic Plast Reconstr Surg. 2021;37(3):e125.

OncoTargets and Therapy

\section{Publish your work in this journal}

OncoTargets and Therapy is an international, peer-reviewed, open access journal focusing on the pathological basis of all cancers, potential targets for therapy and treatment protocols employed to improve the management of cancer patients. The journal also focuses on the impact of management programs and new therapeutic

Submit your manuscript here: https://www.dovepress.com/oncotargets-and-therapy-journal
8. Liu C, Daigle P, Munoz DG, et al. Intravascular papillary endothelial hyperplasia as a cause of reversible vision loss. J Craniofac Surg. 2021;32(3):e296-e298.

9. Eguchi T, Nakaoka K, Basugi A, et al. Intravascular papillary endothelial hyperplasia in the mandible: a case report. $J$ Int Med Res. 2020;48(11):300060520972900. doi:10.1177/ 0300060520972900

10. Susini T, Molino C, Castiglione F, et al. Masson's vegetant hemangioendothelioma arising in the uterine cervix during pregnancy: a case report. $J$ Womens Health. 2010;19(9):1759-1762. doi:10.1089/jwh.2010.1979

11. Akdur NC, Donmez M, Gozel S, et al. Intravascular papillary endothelial hyperplasia: histomorphological and immunohistochemical features. Diagn Pathol. 2013;8(1):167. doi:10.1186/1746-15968-167

12. Mann P, Kleinschmidt-DeMasters BK. CNS masson tumors: frequent association with therapeutic radiation. Am J Surg Pathol. 2016;40 (1):81-93. doi:10.1097/PAS.0000000000000539

13. Jazaerly T, Jaratli H, Sakr W, et al. Intravascular papillary endothelial hyperplasia of the bladder: case report and review of the literature. Avicenna J Med. 2011;1(2):55-57. doi:10.4103/2231-0770.90917

14. Lorente-Ramos RM, Azpeitia Armán J, Martínez Izquierdo MA, et al. Papillary endothelial hyperplasia (Masson's tumor) developed in the capsule of the implant in a breast cancer patient treated with mastectomy and radiation therapy. J Clin Ultrasound. 2020;48 (4):222-226. doi:10.1002/jcu.22807

15. Khazai L, Chau A, Hoover S, et al. Papillary endothelial hyperplasia arising in the irradiated breast: a diagnostic dilemma. Pathol Res Pract. 2016;212(7):604-607. doi:10.1016/j.prp.2015.11.022

16. Perez Prat G, Serrano Jimenez M, Cancela Caro P, et al. Staged management of intracranial masson tumor: an unexpected gauntlet: case report and review of the literature. World Neurosurg. 2018;114:194-203. doi:10.1016/j.wneu.2018.03.054

17. Zhang R, Zhou L-F, Mao Y, et al. Papillary endothelial hyperplasia (masson tumor) of the petrous and jugulare region: case report and literature review. Surg Neurol. 2005;64(1):55-60; discussion 60. doi:10.1016/j.surneu.2004.08.091

18. Sim SY, Lim YC, Won KS, et al. Thirteen-year follow-up of parasellar intravascular papillary endothelial hyperplasia successfully treated by surgical excision: case report. J Neurosurg Pediatr. 2015;15(4):384-391. doi:10.3171/2014.9.PEDS13518

19. Kim T-H, Lee -H-H, Koh E-S. Intravascular papillary endothelial hyperplasia (masson's tumour) in the vulva. Eur J Obstet Gynecol Reprod Biol. 2013;169(2):413-414. doi:10.1016/j.ejogrb.2013.03.034

20. Nwokolo V, Veeramachaneni R, Rivas SD. Vulvar intravascular papillary endothelial hyperplasia or masson's tumor: a case report. Case Rep Womens Health. 2020;28:e0250. doi:10.1016/j.crwh.2020. $\mathrm{e} 00250$

21. Sherring K, Foot O, Barton DP, et al. Ovarian extravascular papillary endothelial hyperplasia (masson tumor) mimicking a primary gynecologic malignancy. Int J Gynecol Pathol. 2020.

agents and protocols on patient perspectives such as quality of life adherence and satisfaction. The manuscript management system is completely online and includes a very quick and fair peer-review system, which is all easy to use. Visit http://www.dovepress.com/ testimonials.php to read real quotes from published authors. 